\title{
Association of $A p o E$ polymorphisms with prevalent hypertension in 1406 older adults: the Bambuí Health Aging Study (BHAS)
}

\author{
A.K. Fuzikawa1 ${ }^{1}$, S.V. Peixoto ${ }^{1}$, M. Taufer ${ }^{2}$, E.H. Moriguchi ${ }^{3}$ and M.F. Lima-Costa ${ }^{1}$ \\ ${ }^{1}$ Núcleo de Estudos em Saúde Pública e Envelhecimento (NESPE), Fundação Oswaldo Cruz, \\ Universidade Federal de Minas Gerais, Belo Horizonte, MG, Brasil \\ ${ }^{2} \mathrm{CMIC}$ Brasil Pesquisas Clínicas, Porto Alegre, RS, Brasil \\ ${ }^{3}$ Universidade Federal do Rio Grande do Sul, Universidade do Vale dos Sinos, Hospital Moinhos de \\ Vento de Porto Alegre, Porto Alegre, RS, Brasil \\ Correspondence to: M.F. Lima-Costa, Laboratório de Epidemiologia e Antropologia Médica, Instituto \\ René Rachou, Fundação Oswaldo Cruz, Av. Augusto de Lima, 1715, 30190-002 Belo Horizonte, MG, \\ Brasil \\ Fax: +55-31-3295-3115. E-mail: lima-costa@cpqrr.fiocruz.br
}

\begin{abstract}
Apolipoprotein $\mathrm{E}(\mathrm{ApoE})$ polymorphism influences lipid metabolism, but its association with arterial hypertension is controversial. The objective of this study was to examine the association between ApoE polymorphism and prevalent hypertension in a large unselected population of older adults. Participants from the baseline of the Bambuí Health Aging Study whose ApoEgenes had been genotyped were selected for this study ( $\mathrm{N}=1406$, aged $60-95$ years). These subjects represented $80.7 \%$ of the total elderly residents in Bambuí city, MG, Brazil. Hypertension was defined as a systolic blood pressure $\geq 140 \mathrm{mmHg}$ and/or a diastolic blood pressure $\geq 90 \mathrm{mmHg}$, or the use of anti-hypertensive medication. The exposure variable was the ApoE genotype as follows: $\varepsilon 3$ carriers, $\varepsilon 3 \varepsilon 3$; $\varepsilon 2$ carriers, $\varepsilon 2 \varepsilon 2$ or $\varepsilon 2 \varepsilon 3$, and $\varepsilon 4$ carriers, $\varepsilon 3 \varepsilon 4$ or $\varepsilon 4 \varepsilon 4$. Potential confounding variables were age, gender, traditional cardiovascular risk factors, uric acid, and creatinine levels. The prevalence of hypertension was $61.3 \%$. Compared with the $\varepsilon 3$ homozygotes, neither the $\varepsilon 2$ nor the $\varepsilon 4$ carrier status was associated with hypertension (adjusted prevalence ratios $=0.94,95 \% \mathrm{Cl}=0.83-1.07$ and $0.98,0.89-1.07$, respectively). On the other hand, the $\varepsilon 2$ allele carriers had lower LDL cholesterol levels $(P<0.001)$ and the $\varepsilon 4$ carriers had higher LDL cholesterol levels $(P=0.036)$. This study provides epidemiologic evidence that the $A p o E$ genotype is not associated with prevalent hypertension in old age.
\end{abstract}

Key words: Apolipoprotein E; Hypertension; Low-density lipoprotein cholesterol; Triglycerides; Lipid metabolism

Research supported by CNPq (No. 470841/2004-4).

Received June 29, 2007. Accepted November 8, 2007

\section{Introduction}

There has been an increasing interest in apolipoprotein $\mathrm{E}(\mathrm{ApoE})$ polymorphisms as predictors of hypertension. ApoE plays a fundamental role in lipid metabolism, participating in the clearance of chylomicron remmants and very low-density lipoproteins (VLDL) by serving as a ligand for low-density lipoprotein (LDL) receptors (1). It is also an important determinant of intestinal cholesterol absorption (2) and plasma lipid levels (3). The ApoE gene is located on chromosome $19(4,5)$ with three common alleles, termed $\varepsilon 2, \varepsilon 3$ and $\varepsilon 4$. The $\varepsilon 4$ allele has consistently been linked to increases in LDL cholesterol levels $(6,7)$. The $\varepsilon 2$ allele has been reported to be linked with higher triglyceride levels in some $(6,8)$, but not all studies (7).

Although $A p o E$ genotype is involved in lipid metabolism, its association with arterial hypertension is controversial. Nevertheless, only two previous studies $(9,10)$ involved populations of more than 1000 subjects, few studies have been carried out in representative community- 
based samples, and few studies have considered traditional risk factors as potential confounders for the association between $A p o E$ and hypertension or blood pressure level (9-21). Aditionally, few studies focused on the influence of $A p o E$ genotype on hypertension in older individuals $(9,12-14)$.

The primary objective of this study was to investigate the effect of the $A p o E$ polymorphisms on the prevalence of hypertension in a population of 1406 community-dwelling older adults, considering several potential confounding factors in the analysis. A secondary objective was to examine the association between ApoE polymorphism and systolic blood pressure, diastolic blood pressure, highdensity lipoprotein (HDL) cholesterol, LDL cholesterol and triglyceride levels.

\section{Material and Methods}

\section{The Bambuí Health Ageing Study (BHAS)}

The BHAS is a population-based cohort of older adults, which has been carried out in Bambuí city ( 15,000 inhabitants), which is situated in Minas Gerais State, Southeastern Brazil. The cohort baseline was established in 1997. From November to December 1996, a complete census was carried out by the research team for identification of participants. Of the 1742 inhabitants aged 60 years or older by January 1, 1997, 1606 (92.0\%) participated. The mean age of the cohort participants was 69.3 years (range: $60-95$ years), and $60.0 \%$ were women. White skin color was predominant $(60.4 \%)$, followed by light brown ("moreno", 33.3\%), dark brown ("mulato", 3.6\%), and black (2.7\%) (22). The prevalence of hypertension (61.5\%) was close to that described for the North American elderly ( $60 \%$ ) (23), as well as the prevalence of some traditional risk factors (24). A detailed description of the study design and methods has been published elsewhere (25).

\section{Study participants}

All of the 1406 cohort members who had their blood pressure $(\mathrm{BP})$ measured at baseline and whose $A p o E$ was genotyped were selected for the present study. The participants in this study were similar to non-participants in relation to age $(P=0.999)$ and gender $(P=0.365)$.

\section{Measurements}

Three measurements of systolic (SBP) and diastolic (DBP) were taken on the right arm with an appropriately sized cuff using a mercury sphygmomanometer. BP measurements were taken early in the morning, after a 5-min initial rest and subsequently at 2-min intervals between each measurement, and after 30 or more min of the last caffeine intake or cigarette smoked. BP was considered as the arithmetic mean of the second and third measurements. According to the Seventh Joint National Committee criteria (26), hypertension was defined as SBP $\geq 140 \mathrm{mmHg}$ and/or DBP $\geq 90 \mathrm{mmHg}$ or the use of anti-hypertensive medication. Current use of anti-hypertensive medication was ascertained by reviewing medication containers or prescription, and coding the medication as previously described (27).

Genomic DNA for ApoE genotyping was extracted from blood samples using the Wizard $^{\circledR}$ Genomic DNA Purification System (Promega, Madison, WI, USA). DNA samples were then amplified by polymerase chain reaction (PCR), followed by digestion with Hhal, and restriction fragment length polymorphism analysis, as previously described (28). The DNA samples were subjected to PCR with the following primers: forward 5' TAA GCT TGG CAC GGC TGT CCA AGG A 3' and reverse 5' ACA GAA TTC GCC CCG GCC TGG TAC AC 3'. The PCR conditions were denaturation at $95^{\circ} \mathrm{C}$ for $5 \mathrm{~min}$, followed by 35 cycles of $95^{\circ} \mathrm{C}$ for $1 \mathrm{~min}, 60^{\circ} \mathrm{C}$ for $1 \mathrm{~min}$, and $70^{\circ} \mathrm{C}$ for $2 \mathrm{~min}$, and a final extension at $72^{\circ} \mathrm{C}$ for $10 \mathrm{~min}$. Restriction fragment length polymorphism analysis yielded the following patterns: $\varepsilon 2 \varepsilon 2$, 91 and 83 bp; $\varepsilon 3 \varepsilon 3,91$, 48 and 35 bp; $\varepsilon 4 \varepsilon 4,72$, 48 and 35 bp. Each of the heterozygote genotypes contained both sets of fragments from each $A p o E$ allele.

Other variables considered included baseline age, gender, smoking, alcohol consumption, physical activity, family history of cardiovascular diseases, diabetes, traditional risk factors for cardiovascular diseases such as SBP, DBP, body mass index (BMI), and levels of LDL cholesterol, HDL cholesterol, triglycerides, creatinine (29), and uric acid (30). Current smokers were defined as those who had smoked at least 100 cigarettes during their lifetime and were still smoking. For alcohol consumption estimates, the subjects were shown cards with a representation of the amount of liquid corresponding to one drink for liquor, beer or wine. The alcohol consumption was calculated by multiplying the number of drinks by the frequency of imbibing in a week during the previous 12 months. Physical activity was defined as any exercise for 20-30 min at least three times a week, during leisure time in the previous 90 days. Diabetes was defined by a fasting blood glucose level $\geq 126 \mathrm{mg} / \mathrm{dL}$ and/or current use of insulin or oral antidiabetic drug treatment, as defined by the 2003 American Diabetes Association updated criteria (31). BMI (weight/ height $^{2}$ ) was calculated from height and weight measurements. Levels of LDL cholesterol, HDL cholesterol, triglycerides, creatinine, and uric acid were determined after a 12-h recommended overnight fast, using commercial kits (Boehringer Mannhein, Germany) and an automated ana- 
lyzer (Eclipse Vitalab, Merck, Netherlands), as described elsewhere (25).

All of the observers of the BHAS were trained and certified before each examination. The BHAS was approved by the Ethics Committee of the Oswaldo Cruz Foundation in Rio de Janeiro, RJ, Brazil, in 1996, and the present investigation was approved by the Ethics Committee of the Oswaldo Cruz Foundation in Belo Horizonte, MG, Brazil, in 2006. All participants gave full informed written consent.

\section{Statistical analysis}

The statistical analysis was performed by using the Stata version 9.1 software (Stata Corporation, College Station, TX, USA). Allele frequencies were estimated by gene counting. Hardy-Weinberg equilibrium expectations were tested by using a chi-square $\left(\chi^{2}\right)$ goodness-of-fit test. Non-adjusted analysis of the association between $A p o E$ genotypes and alleles with prevalent hypertension was based on Person's chi-square test. Age-gender adjusted means and standard errors of the mean by $A p o E$ genotype were calculated for baseline SBP, DBP, LDL cholesterol, HDL cholesterol, and triglyceride levels. Multiple linear regression was used to assess the association between $A p o E$ genotype and the above mentioned parameters, after adjustments for age and gender. Poisson regression models (32) were used to estimate the prevalence ratio for hypertension. The models included age and gender in model 1, and age, gender, smoking, alcohol consumption, physical activity, family history, diabetes, LDL cholesterol, HDL cholesterol, uric acid, creatinine, and BMI in model 2. In the adjusted analysis, $A p o E$ genotypes were classified into three groups: $\varepsilon 3$ carriers $(\varepsilon 3 \varepsilon 3)$, $\varepsilon 2$ carriers $(\varepsilon 2 \varepsilon 2$, $\varepsilon 2 \varepsilon 3)$ and $\varepsilon 4$ carriers $(\varepsilon 4 \varepsilon 4, \varepsilon 3 \varepsilon 4)$. In each model, the homozygous $\varepsilon 3 \varepsilon 3$ genotype was the reference group. Twenty subjects (1.4\%) with the $\varepsilon 2 \varepsilon 4$ genotype were excluded from the analysis because of the opposite effects of these two alleles on LDL cholesterol levels. Since no effect modification by gender was noted, all analyses were for both sexes. Statistical significance in the models was assessed using Wald $\chi^{2}$ statistics.

\section{Results}

The prevalence of hypertension was $61.3 \%$ for the 1406 participants in the BHAS baseline. As found in most western populations, the $\varepsilon 3 \varepsilon 3$ genotype was the most common (63.4\%), followed by $\varepsilon 3 \varepsilon 4(21.9 \%), \varepsilon 2 \varepsilon 3(11.5 \%)$, $\varepsilon 4 \varepsilon 4(1.8 \%), \varepsilon 2 \varepsilon 4(1.4 \%)$, and $\varepsilon 2 \varepsilon 2(0.1 \%)$. Allele frequencies were within the Hardy-Weinberg equilibrium expectations $(P>0.05)$. Additional baseline characteristics of the study participants are shown in Table 1.

Selected baseline characteristics of the BHAS population by $A p o E$ genotypes, adjusted for age and gender are shown in Table 2. The mean LDL cholesterol was signifi-

Table 1. Selected baseline characteristics of the 1406 participants from the Bambui Health and Aging Study (BHAS).

\begin{tabular}{lc}
\hline Characteristics & $\begin{array}{c}\text { Percentage or mean } \\
\text { (standard deviation) }\end{array}$ \\
\hline Age (years) & $69.1(7.1)$ \\
Female gender & $60.5 \%$ \\
Current smokers & $18.1 \%$ \\
Alcohol consumption in the previous 12 & $2.8 \%$ \\
$\quad$ months (>14 doses a week) & $12.5 \%$ \\
Exercises lasting 20-30 min three times & \\
$\quad$ a week or more during the previous 3 months \\
Family history of cardiovascular diseases & $45.9 \%$ \\
Diabetes mellitus & $14.1 \%$ \\
Systolic blood pressure (mmHg) & $137.2(22.6)$ \\
Diastolic blood pressure (mmHg) & $83.6(12.7)$ \\
Body mass index (kg/m 2 ) & $25.0(4.9)$ \\
LDL cholesterol (mg/dL) & $155.0(45.4)$ \\
HDL cholesterol (mg/dL) & $49.1(15.1)$ \\
Triglycerides $(\mathrm{mg} / \mathrm{dL})$ & $151.1(100.3)$ \\
Creatinine $(\mathrm{mg} / \mathrm{dL})$ & $0.90(0.30)$ \\
Uric acid (mg/dL) & $5.3(1.7)$ \\
\hline
\end{tabular}

Table 2. Age-sex adjusted analysis of the association between selected baseline characteristics of the Bambuí Health and Aging Study (BHAS) population and $A p o E$ genotype.

\begin{tabular}{|c|c|c|c|c|c|c|}
\hline \multirow[t]{2}{*}{ ApoE genotype } & \multirow[t]{2}{*}{$\mathrm{N}$} & \multicolumn{5}{|c|}{ Characteristics } \\
\hline & & $\begin{array}{c}\text { Systolic blood } \\
\text { pressure }(\mathrm{mmHg})\end{array}$ & $\begin{array}{l}\text { Diastolic blood } \\
\text { pressure }(\mathrm{mmHg})\end{array}$ & $\begin{array}{l}\text { LDL cholesterol } \\
(\mathrm{mg} / \mathrm{dL})\end{array}$ & $\begin{array}{l}\text { HDL cholesterol } \\
(\mathrm{mg} / \mathrm{dL})\end{array}$ & $\begin{array}{l}\text { Triglycerides } \\
(\mathrm{mg} / \mathrm{dL})\end{array}$ \\
\hline$\varepsilon 3 \varepsilon 3$ & 891 & $137.25(0.75)$ & $83.59(0.42)$ & $155.85(1.50)$ & $48.99(0.49)$ & $147.63(3.34)$ \\
\hline$\varepsilon 2 \varepsilon 2, \varepsilon 2 \varepsilon 3$ & 162 & $136.80(1.76)$ & $83.88(0.99)$ & $140.46(3.56)^{*}$ & 50.95 (1.16) & $167.11(7.84)^{\star \star \star *}$ \\
\hline$\varepsilon 3 \varepsilon 4, \varepsilon 4 \varepsilon 4$ & 333 & $137.16(1.23)$ & $83.53(0.69)$ & $161.91(2.47)^{\star *}$ & $48.20(0.81)$ & $153.63(5.47)$ \\
\hline
\end{tabular}

Data are reported as means (standard error of the mean) adjusted for age and gender.

${ }^{*} \mathrm{P}<0.001 ;{ }^{* *} \mathrm{P}=0.036 ;{ }^{* * *} \mathrm{P}=0.022$ compared to $\varepsilon 3 \varepsilon 3$ (multiple linear regression). 
cantly greater among the $\varepsilon 4$ carriers $(P=0.036)$ and lower among the $\varepsilon 2$ carriers $(P<0.001)$, in comparison to the homozygous $\varepsilon 3 \varepsilon 3$ carriers. The mean triglyceride level was significantly greater among those with the $\varepsilon 2$ allele $(P$ $=0.022)$. No significant associations were found between ApoE genotype and SBP, DBP and HDL cholesterol levels.

The ApoE genotype and allele frequencies for the prevalence of hypertension are shown in Table 3. Both the ApoE genotype and the allele frequencies showed similar distributions among prevalent hypertension cases and non-cases.

The results of the adjusted analysis for the association

Table 3. Non-adjusted analysis of the association between $A p o E$ polymorphism and hypertension in the Bambuí Health and Aging Study (BHAS) population.

\begin{tabular}{lcc}
\hline & \multicolumn{2}{c}{ Hypertension } \\
\cline { 2 - 3 } & Yes & No \\
\hline ApoE genotype & & \\
$\varepsilon 2 \varepsilon 2$ & $1(0.1 \%)$ & $0(0.0 \%)$ \\
$\varepsilon 2 \varepsilon 3$ & $95(11.0 \%)$ & $66(12.1 \%)$ \\
$\varepsilon 2 \varepsilon 4$ & $13(1.5 \%)$ & $7(1.3 \%)$ \\
$\varepsilon 3 \varepsilon 3$ & $556(64.5 \%)$ & $335(61.6 \%)$ \\
$\varepsilon 3 \varepsilon 4$ & $179(20.8 \%)$ & $129(23.7 \%)$ \\
$\varepsilon 4 \varepsilon 4$ & $18(2.1 \%)$ & $7(1.3 \%)$ \\
$\mathrm{P}=0.538$ & & \\
ApoE allele & & $73(6.7 \%)$ \\
$\varepsilon 2$ & $110(6.4 \%)$ & $865(79.5 \%)$ \\
$\varepsilon 3$ & $1386(80.4 \%)$ & $150(13.8 \%)$ \\
$\varepsilon 4$ & $228(13.2 \%)$ & \\
$\mathrm{P}=0.846$ & & \\
\hline
\end{tabular}

Data are reported as number of subjects with percent in parentheses.

${ }^{*} \mathrm{P}$ value: Person's chi-square test.

Table 4. Poisson regression models and prevalence ratio for hypertension in the Bambuí Health and Aging Study (BHAS) population, by ApoE genotype.

\begin{tabular}{lrrcc}
\hline ApoE genotype N & $\begin{array}{c}\text { Hypertension } \\
\text { prevalence (\%) }\end{array}$ & $\begin{array}{c}\text { Model 1 } \\
\text { PR }(95 \% \mathrm{Cl})\end{array}$ & $\begin{array}{c}\text { Model 2 } \\
\text { PR }(95 \% \mathrm{Cl})\end{array}$ \\
\hline$\varepsilon 3 \varepsilon 3$ & 891 & $556(62.4 \%)$ & 1.0 & 1.0 \\
$\varepsilon 2 \varepsilon 2, \varepsilon 2 \varepsilon 3$ & 162 & $96(59.3 \%)$ & $0.96(0.83-1.09)$ & $0.94(0.83-1.07)$ \\
$\varepsilon 3 \varepsilon 4, \varepsilon 4 \varepsilon 4$ & 333 & $197(59.2 \%)$ & $0.95(0.86-1.05)$ & $0.98(0.89-1.07)$ \\
\hline
\end{tabular}

Model 1: Adjusted for age and gender. Model 2: Adjusted for age, gender, smoking, alcohol consumption, physical activity, family history, diabetes, LDL cholesterol, HDL cholesterol, uric acid, creatinine, and body mass index. $\mathrm{PR}=$ prevalence ratio (95\% robust confidence intervals). between ApoE genotype and hypertension are shown in Table 4. Hypertension was not associated with the presence of either $\varepsilon 2$ or $\varepsilon 4$ alleles in the model adjusted by age and gender or in the model adjusted for several confounders.

\section{Discussion}

In this study, prevalent hypertension was not associated with $A p o E$ polymorphisms in a large sample of Brazilian older adults. This lack of association was observed in the age-gender adjusted analysis and in the analysis adjusted for factors a prioribelieved to be potential confounders for the association between ApoE genotype and hypertension. Secondary analysis indicated that such associations were absent for both males and females (data not shown).

An association was observed between greater LDL cholesterol levels and the presence of the $\varepsilon 4$ allele, as well as between lower LDL cholesterol levels and the presence of the $\varepsilon 2$ allele. This observation is in agreement with other studies reporting a consistent relationship between the $\varepsilon 4$ allele and greater levels of LDL cholesterol $(6,7)$, as well as between the $\varepsilon 2$ allele and lower LDL cholesterol levels (6). Higher triglyceride levels were found in $\varepsilon 2$ carriers. This association was reported in some $(6,8)$, but not all previous investigations (7). The association of the ApoE alleles with plasma lipid levels is a direct consequence of the role of ApoE protein in lipid metabolism. ApoE2 is metabolically impaired when compared to ApoE3 and ApoE4, due to its reduced interaction with cellular receptors, resulting in delayed clearance and accumulation of chylomicrons and VLDL remnants in the plasma. ApoE-mediated LDL conversion from VLDL remnants is also reduced. The net effect is an up-regulation of LDL receptors, higher plasma concentrations of triglyceride- and cholesterol-containing remnant particles, and lower plasma levels of cholesterolrich LDL particles (1). ApoE4 alleles have an opposite net effect compared to those of ApoE2 $(1,3)$.

There have been several studies of the association between the $A p o E$ genotypes and prevalent hypertension, with inconsistent findings. Results from small prevalent case control studies have consistently described a positive relationship between the presence of the $\varepsilon 4$ allele and hypertension or with greater BP levels (15-19). The results from cross-sectional studies have been more inconsistent. Four investigations carried out in an mixed population of younger and older adults reported i) lack of association between the ApoE genotype and hypertension in the USA (10) and in Tunisia (11), ii) a positive association between the $\varepsilon 2$ allele and prevalent hypertension among male, but 
not female, Japanese immigrants living in Los Angeles or Hawaii (20), and iii) a negative association between the presence of the $\varepsilon 4$ allele and prevalent hypertension in young, but not older, Japanese (9). Three other crosssectional studies included very old subjects. Two were carried out in Finland (12) and in Spain (14), and did not find significant association between ApoE genotype, prevalent hypertension (14), or mean SBP and mean DBP (12). The third study included Italian descendents living in the south of Brazil and reported a significantly lower DBP among the $\varepsilon 4$ carriers, compared to the homozygous $\varepsilon 3 \varepsilon 3$, but the mean SBP was similar in both groups (13). In addition, two cohort studies carried out with Japanese Americans (20) and North American males (21) reported contradictory results. In the present study, the mean baseline SBP and DBP, as well as prevalent hypertension, were not associated with the ApoE genotype.

\section{REFERENCES}

1. Mahley RW, Innerarity TL, Rall SC Jr, Weisgraber $\mathrm{KH}$. Plasma lipoproteins: apolipoprotein structure and function. J Lipid Res 1984; 25: 1277-1294.

2. Kesaniemi YA, Ehnholm C, Miettinen TA. Intestinal cholesterol absorption efficiency in man is related to apoprotein $\mathrm{E}$ phenotype. J Clin Invest 1987; 80: 578-581.

3. Davignon J, Gregg RE, Sing CF. Apolipoprotein E polymorphism and atherosclerosis. Arteriosclerosis 1988; 8: 1-21.

4. Das HK, McPherson J, Bruns GA, Karathanasis SK, Breslow JL. Isolation, characterization, and mapping to chromosome 19 of the human apolipoprotein E gene. J Biol Chem 1985; 260: 6240-6247.

5. Paik YK, Chang DJ, Reardon CA, Davies GE, Mahley RW, Taylor JM. Nucleotide sequence and structure of the human apolipoprotein E gene. Proc Natl Acad Sci U S A 1985; 82: 3445-3449.

6. Howard BV, Gidding SS, Liu K. Association of apolipoprotein $\mathrm{E}$ phenotype with plasma lipoproteins in African-American and white young adults. The CARDIA Study. Coronary artery risk development in young adults. Am J Epidemiol 1998; 148: 859-868.

7. Volcik KA, Barkley RA, Hutchinson RG, Mosley TH, Heiss $G$, Sharrett AR, et al. Apolipoprotein E polymorphisms predict low-density lipoprotein cholesterol levels and carotid artery wall thickness but not incident coronary heart disease in 12,491 ARIC study participants. Am J Epidemiol 2006; 164: 342-348.

8. Dallongeville J, Lussier-Cacan S, Davignon J. Modulation of plasma triglyceride levels by $A p o E$ phenotype: a meta-analysis. J Lipid Res 1992; 33: 447-454.

9. Katsuya T, Baba S, Ishikawa K, Mannami T, Fu Y, Inamoto $\mathrm{N}$, et al. Epsilon 4 allele of apolipoprotein $\mathrm{E}$ gene associates with lower blood pressure in young Japanese subjects: the Suita Study. J Hypertens 2002; 20: 2017-2021.

10. Wilson PW, Myers RH, Larson MG, Ordovas JM, Wolf PA,
This investigation benefits from a large number of subjects, the use of an unselected community-based population, and the use of double-blind data collection, as the technicians were unaware of the participants' $A p o E$ or hypertension status. Selection and information bias are therefore unlikely, but prevalence bias is a potential limitation. The population investigated here consisted of older adults; therefore, the results may not be relevant to younger subjects.

In conclusion, this study confirms that the presence of the $\varepsilon 4$ allele is associated with greater LDL cholesterol levels and the presence of the $\varepsilon 2$ allele is associated with lower LDL levels and greater triglyceride levels. This investigation also provides epidemiologic evidence that $A p o E$ genotype is not associated with prevalent hypertension in old age.
Schaefer EJ. Apolipoprotein E alleles, dyslipidemia, and coronary heart disease. The Framingham Offspring Study. JAMA 1994; 272: 1666-1671.

11. Jemaa R, Elasmi M, Naouali C, Feki M, Kallel A, Souissi M, et al. Apolipoprotein $\mathrm{E}$ polymorphism in the Tunisian population: frequency and effect on lipid parameters. Clin Biochem 2006; 39: 816-820.

12. Rastas S, Mattila K, Verkkoniemi A, Niinisto L, Juva K, Sulkava R, et al. Association of apolipoprotein E genotypes, blood pressure, blood lipids and ECG abnormalities in a general population aged 85+. BMC Geriatr 2004; $4: 1$.

13. Schwanke $\mathrm{CH}$, da Cruz I, Leal NF, Scheibe R, Moriguchi $Y$, Moriguchi EH. Analysis of the association between apolipoprotein $\mathrm{E}$ polymorphism and cardiovascular risk factors in an elderly population with longevity. Arq Bras Cardiol 2002; 78: 561-579.

14. Formiga F, Alia P, Navarro MA, Pujol R. Apolipoprotein e genotypes in nonagenarians. J Am Geriatr Soc 2006; 54: 1471-1473.

15. Bhavani AB, Sastry KB, Reddy NK, Padma T. Lipid profile and apolipoprotein $\mathrm{E}$ polymorphism in essential hypertension. Indian Heart J 2005; 57: 151-157.

16. Isbir T, Yilmaz H, Bihorac A, Akoglu E. Mild-to-moderate hypertension and apolipoprotein $\mathrm{E}$ gene polymorphism. Am J Hypertens 1997; 10: 827-828.

17. Li X, Du Y, Du Y, Huang X. Association of apolipoprotein $E$ gene polymorphism with essential hypertension and its complications. Clin Exp Med 2003; 2: 175-179.

18. Niu W, Guo X, Su Y, Qiu C. Apolipoprotein E and lowdensity lipoprotein receptor gene polymorphisms in dyslipidemias-associated essential hypertension. J Hum Hypertens 2007; 21: 337-339.

19. Yilmaz H, Isbir T, Agachan B, Aydin M. Is epsilon4 allele of apolipoprotein $E$ associated with more severe end-organ damage in essential hypertension? Cell Biochem Funct 
2001; 19: 191-195.

20. Imazu M, Yamamoto H, Toyofuku M, Watanabe T, Okubo $M$, Egusa $G$, et al. Association of apolipoprotein $E$ phenotype with hypertension in Japanese-Americans: data from the Hawaii-Los Angeles-Hiroshima Study. Hypertens Res 2001; 24: 523-529.

21. Scuteri A, Najjar SS, Muller D, Andres $\mathrm{R}$, Morrell $\mathrm{CH}$, Zonderman $\mathrm{AB}$, et al. ApoE4 allele and the natural history of cardiovascular risk factors. Am J Physiol Endocrinol Metab 2005; 289: E322-E327.

22. Fuzikawa AK, Peixoto SV, Taufer M, Moriguchi EH, LimaCosta MF. Apolipoprotein E polymorphism distribution in an elderly Brazilian population: the Bambuí Health and Aging Study. Braz J Med Biol Res 2007; 40: 1429-1434.

23. Barreto SM, Passos VM, Firmo JO, Guerra HL, Vidigal PG, Lima-Costa MF. Hypertension and clustering of cardiovascular risk factors in a community in Southeast Brazil - The Bambuí Health and Ageing Study. Arq Bras Cardiol 2001; 77: $576-581$.

24. Lima-Costa MF, Barreto SM, Uchoa E, Firmo JO, Vidigal PG, Guerra HL. The Bambuí Health and Aging Study (BHAS): prevalence of risk factors and use of preventive health care services. Rev Panam Salud Publica 2001; 9: 219-227.

25. Costa MF, Uchoa E, Guerra HL, Firmo JO, Vidigal PG, Barreto SM. The Bambuí health and ageing study (BHAS): methodological approach and preliminary results of a population-based cohort study of the elderly in Brazil. Rev Saúde
Pública 2000; 34: 126-135

26. Chobanian AV, Bakris GL, Black HR, Cushman WC, Green LA, Izzo JL Jr, et al. The Seventh Report of the Joint National Committee on Prevention, Detection, Evaluation, and Treatment of High Blood Pressure: the JNC 7 report. JAMA 2003; 289: 2560-2572.

27. World Health Organization. Anatomical Therapeutical Chemical (ATC) classification index with Defined Daily Doses (DDDs). http://www.whocc. no/atcddd/indexdata base. Accessed February 10, 2005.

28. Hixson JE, Vernier DT. Restriction isotyping of human apolipoprotein $\mathrm{E}$ by gene amplification and cleavage with Hhal. J Lipid Res 1990; 31: 545-548.

29. Wattanakit K, Folsom AR, Chambless LE, Nieto FJ. Risk factors for cardiovascular event recurrence in the Atherosclerosis Risk in Communities (ARIC) study. Am Heart $J$ 2005; 149: 606-612.

30. Sundstrom J, Sullivan L, D'Agostino RB, Levy D, Kannel WB, Vasan RS. Relations of serum uric acid to longitudinal blood pressure tracking and hypertension incidence. Hypertension 2005; 45: 28-33.

31. Genuth S, Alberti KG, Bennett P, Buse J, Defronzo R, Kahn $\mathrm{R}$, et al. Follow-up report on the diagnosis of diabetes mellitus. Diabetes Care 2003; 26: 3160-3167.

32. Zou G. A modified poisson regression approach to prospective studies with binary data. Am J Epidemiol 2004; 159: 702-706. 